Review

\title{
A Critical Review of Research on Reuse of Mechanically Recycled FRP Production and End-of-Life Waste for Construction
}

\author{
Ardavan Yazdanbakhsh * and Lawrence C. Bank \\ Civil Engineering Department, City College of New York, New York, NY 10031, USA \\ * Author to whom correspondence should be addressed; E-Mail: ayazdanbakhsh@ccny.cuny.edu; \\ Tel.: +1-212-650-6569; Fax: +1-212-650-6965.
}

Received: 25 April 2014; in revised form: 28 May 2014 / Accepted: 4 June 2014 /

Published: 17 June 2014

\begin{abstract}
For the last three decades, fiber reinforced polymer (FRP) composite materials have been widely used in major engineering industries. Managing FRP waste is becoming an important issue due to the growth in the production of FRP composite materials. In this article, the issue of FRP waste management is discussed and the commonly used methods for the handling of FRP waste are reviewed. One potentially viable use of FRP waste is in the partial replacement of fillers or aggregates in cementitious materials (particularly portland cement mortar and concrete). A number of important prior investigations performed on the use of FRP waste in concrete and mortar are reviewed. The results from most of those investigations suggest that FRP aggregates significantly reduce the strength of cementitious materials with little significant effect on durability. Recommendations for future research in this area are provided for producing stronger mortars and concretes incorporating FRP production and end-of-life waste.
\end{abstract}

Keywords: aggregate; concrete; fiber reinforced polymer; filler; mechanical properties; recycling; reuse

\section{Introduction}

Fiber-reinforced polymer (FRP) composite materials are used extensively and increasingly in major industries including aerospace, marine, construction, electrical, automotive, domestic appliances, furniture, and sports equipment. FRP composite materials used in these industries typically consist of glass, carbon, or aramid fibers, which are either continuous or discreet, encased in a matrix of 
thermosetting resins that have fiber concentrations typically in the range of $12 \%-60 \%$ by volume [1], and inorganic fillers (also known as "extenders") typically in the range of zero to $20 \%$ by volume. Some types of polymer composites such as bulk molding compounds (BMC) can contain fillers (usually calcium carbonate, talcum, or mica powders) with up to $50 \%$ of the composite weight (which for BMC materials is close to the volume fraction) [2]. FRP composite materials have important advantages over many traditional construction engineering materials (such as steel and concrete, and timber (wood) in certain circumstances). Those advantages typically include lower densities (i.e., light weight), higher mechanical properties in certain directions, ease of production in different shapes, ease of installation, and greater durability in harsh chemical and aqueous environments. Disadvantages relative to conventional construction materials typically include higher costs, lower temperature resistance and fire performance, lack of standard profiles and parts, lack of accepted material and design specifications, and difficulty of recycling. According to the American Composite Manufacturers Association (ACMA), one of the first known FRP products was produced less than a century ago (in the mid-1930s) in an experimental production of a boat hull using fiberglass fabric and polyester resin [3]. The use of FRP components for civil engineering structures started to become popular in the mid-1990s [4]. The use of FRP in the marine industry started about six decades ago and has led to increasing number of reinforced plastic recreational and working boats, the vast majority being fiberglass (glass fiber reinforced polyester). The International Council of Marine Industry Associations (ICOMIA) has estimated that there are more than 6 million recreational boats in Europe alone [5]. Because FRP composite materials are highly durable, end-of-life disposal has not been a major issue to-date. However, the number of the FRP-incorporated vessels and structural members that are approaching the end of their service or functional lives is increasing rapidly resulting in a growing rate of waste accumulation. Another source of FRP waste is the scrap from the production process of FRP materials, parts and sections; in all production processes portions of the raw material and the final product are rendered unusable. The total combined volume of end-of-life and production waste generated by the glass thermoset composites market in Europe is expected to reach 304,000 tonnes (metric tons) by 2015 [6].

It is predicted that in the U.S. the demand for FRP will climb to nearly 2 million tonnes in 2017 [7]. According to the European Composites Industry Association (EuCIA), in 2013 approximately 1.02 million tonnes of glass fiber reinforced polymer (GFRP) composite materials were manufactured in Europe [8]. In 2010, Osmani and Asokan [9] reported that in the United Kingdom alone the annual production of GFRP waste was around 55,000 tonnes with an expected annual production increases of $10 \%$. Most of the production and end-of-life disposal waste is landfilled. According to Osmani and Asokan, in the United Kingdom, about 90\% of the GFRP waste is landfilled [9].

Since unlike many of the widely used materials - particularly metals, wood, and concrete — recycling and reusing FRP waste is more difficult and expensive. Finding an application for minimally recycled FRP waste will be particularly valuable as it reduces the amount of FRP waste disposed of in landfill sites and the associated high costs. One of those potential applications is using FRP waste as a partial replacement of filler (aggregate) in portland cement mortar and concrete. In this review article, (1) the currently used methods for FRP waste recovery and recycling are discussed, (2) past work on incorporating recycled FRP in cementitious materials is reviewed, and (3) suggestions are made for further investigations to study the viability of using FRP waste in concrete. 


\section{Fiber-Reinforced Polymer (FRP) Waste Management Methods}

FRP waste can sometimes be directly used in construction. For example, the scrap generated from the production of glass fibers reinforced polymer (GFRP) reinforcing bars (typically in the form of short rebars, or defected rebars with poorly bonded glass fibers) can be used in less-structurally-sensitive concrete such as flatwork and slabs on ground. In addition to the direct reuse of FRP waste, there are three main ways to manage FRP waste: (1) landfilling, (2) incineration, and (3) recycling. Landfilling remains the most popular solution to manage FRP waste [10]. Producing FRP and manufacturing FRP members leaves a notable amount of waste. In highly efficient processes such as pultrusion, waste (scrap) is in the range of $3 \%-5 \%$, while in less efficient hand lay-up processes, it typically approaches $15 \%[11,12]$. In aerospace production, CRFP pre-preg scrap can approach $40 \%$ [12]. An average value of $10 \%$ is reported in [11]. Landfilling costs are predicted to increase sufficiently to discourage waste disposal in the future [13]. The high costs of landfilling FRP waste increases the overall cost of FRP products. At the time of preparing this article, the cost of FRP waste management (including pickup and landfilling the scraps) in the U.S. was in the range of \$45-\$200 per tonne. In addition, landfilling is the least sustainable option. In several European Union countries, including Germany, landfilling regulations for FRP waste are very strict [14].

Incineration is a less-commonly adopted method for disposal of thermoset polymer composites including FRP composite waste [15,16]. Incineration allows some energy recovery from the heat produced during the combustion process due to the high calorific value of FRP materials [17]. However, the cost of FRP incineration is higher than landfilling. In general, incineration facilities charge more for incinerating FRP waste because both the high calorific content and the toxic emissions tend to overload the system, meaning they can only process a limited amount of waste [13]. An additional problem with the incineration of GFRP is that about $50 \%-70 \%$ of the residue material is mineral and is left as ash, which still needs to be landfilled. A co-processing method known as the "cement-kiln" method that shares similarities with incineration has been introduced in Germany [14,18]. In this method, size-reduced GFRP waste is fed to a cement production kiln as a raw material for the production of cement clinker and as a secondary fuel. In the kiln, the organic resin burns, providing energy, and the mineral (from the fibers and the fillers) constituent turns into calcium oxide, which is the primary component of portland cement, and provides feedstock for the cement clinker.

Considering the increasing costs, environmental issues, and legislative limitations associated with landfilling and incinerating FRP waste, recycling and reusing waste is becoming an increasingly viable alternative for managing FRP waste. Recycling FRP can be categorized into two main groups: (1) reclaiming the fibers from the polymeric matrix, and (2) mechanical recycling [19]. Fiber reclamation consists of recovering the fibers from the FRP, typically by employing an aggressive thermal or chemical process to break-down the thermoset matrix so that the fibers can be released and collected. Fiber reclamation processes can be attractive options for recycling carbon fiber reinforced polymer (CFRP) materials for two reasons: (1) carbon fibers have high chemical stability [10], and usually their superior mechanical properties are not significantly affected during reclamation, and (2) reclamation processes are costly and have economic justification only for extracting expensive filaments such as carbon fibers. Several companies have been reclaiming and reusing high-value carbon fiber from CFRP waste [20]. Companies such as Boeing and Airbus have invested in efforts to 
recycle carbon composites in order to develop methods that are as robust as those for aluminum, steel and other metals and achieve high recycling percentages [21]. While recently some successful efforts have been made for reclaiming glass fibers from GFRP waste, it is not yet economical to reclaim lower cost glass fibers [22-24].

An overview on carbon fiber reclamation processes is presented by Pimenta and Pinho [19]. Three main methods have been used for fiber reclamation: (1) pyrolysis, (2) oxidation, and (3) chemical recycling. Pyrolysis is the thermal decomposition of organic molecules in an inert atmosphere (e.g., Nitrogen), and is one of the most widespread recycling processes for CFRP. During pyrolysis, the CFRP is heated up to $450-700{ }^{\circ} \mathrm{C}$. In this temperature range, the polymeric matrix is volatilized into lower-weight molecules, while the fibers are minimally affected and recovered [25]. Oxidation is another well-documented thermal process in which the polymeric matrix is combusted in a hot and oxygen-rich flow of a gas such as air [10,26]. Compared to pyrolysis, this method has a higher tolerance to waste contamination, but can result in shortening and significant strength loss of fibers [19]. In chemical recycling (also known as solvolysis), FRP waste is exposed to a reactive material such an acid under low temperature (typically less than $350{ }^{\circ} \mathrm{C}$ ), resulting in the decomposition and separation of the polymeric matrix material $[27,28]$. Chemical methods can, however, cause negative environmental impacts if they make use of hazardous materials.

Mechanical recycling started commercially in the 1970s [14]. There are different types of mechanical recycling, though all of them involve breaking down the composite material and successively reducing the particle size of recycled materials through shredding, crushing, milling, or other similar mechanical process; the resulting scrap pieces can then be segregated, by using sieves and cyclones, into powdered products (rich in resin) and fibrous products (rich in fibers) [10,29]. Mechanical recycling is the most widely used approach for recycling FRP thermoset polymeric fibrous composite materials $[28,30]$. Finally, there are recycling techniques that can be performed and be used for producing specific types of FRP products. For example, Adams et al. [28] developed a method that incorporates splitting, crushing, and hot forming of GFRP sheets obtained from boat hulls to create new GFRP plates and tubes. They showed that by using their method over $50 \%$ of the original mechanical properties, such as the Young's modulus, tensile strength, and interlaminar shear strength, can be retained.

\section{Applications of Recycled FRP Waste in Cementitious Materials}

Mechanical processing remains the most commonly-used method for processing the waste from FRP composite materials. Mechanically recycled FRP waste has a potential application as filler in portland cement mortar and concrete. Limited investigations have been performed on this topic and are discussed in this section.

\subsection{Durability and Physical Properties}

Some of the prior studies suggest that the partial replacement of fine aggregates with mechanically recycled FRP does not affect the durability of portland cement concrete and mortar negatively. Tittarelli and Moriconi [31] investigated the alkali-silica reactivity (ASR) of ground GFRP using the chemical method prescribed by American Society for Testing and Materials (ASTM) [32]. The results 
did not show any potential deleterious reactivity due to the glassy part present in the waste. Moreover, good durability of polyester, vinylester and epoxy resins against alkali attack (another durability issue) is generally reported in the literature [33]. FRP reinforcing bars (rebars) for concrete reinforcement are a well-accepted product in construction for this reason [34]. Also, Tittarelli and Moriconi found that capillary water absorption and drying shrinkage of cement-based materials with the GFRP addition resulted in significantly lower values than those of the cement-based materials manufactured without the GFRP addition. The findings from the investigations of Asokan et al. [35] showed that there was almost no drying shrinkage of concrete with addition of ground GFRP waste powder. Tittarelli et al. [36,37] reported that in mortars the risk of cracking induced by restrained drying shrinkage and capillary water absorption is significantly lower in the presence of GFRP powder. However, there are downsides to utilizing FRP waste in cementitious materials. For example, fine FRP particles can reduce the workability of concrete due to their high surface area, and in order to maintain the workability a notable change in $w / c$ ratio or the addition of a significant amount of superplasticizer is required [38,39]. However, Tittarelli and Shah [6] observed that ground GFRP reduced the viscosity of cement paste and did so more effectively than fly ash. Tittarelli et al. [36] reported that replacing 5\%-10\% of sand volume with ground GFRP causes an increase in autogenous shrinkage. They also found that the addition of ground GFRP delays the setting time of cement paste. Finally, Tittarelli [37] found that the addition of GFRP dust improves thermal insulation properties. They also observed that GFRP dust reduces the salt crystallization (efflorescence) on the surface of mortar specimens which have been immersed in $\mathrm{NaCl}$ and $\mathrm{Na}_{2} \mathrm{SO}_{4}$ solutions.

While from these limited studies it appears that finely ground FRP filler does not affect the durability of cementitious materials, in order to obtain conclusive results, further durability tests must be performed on different types and sizes of recycled FRP waste as well as on the mortars and concretes which incorporate them. In addition, rheology investigations should be performed to determine the size range of ground FRP that has the most significant effect on the workability of fresh cement paste (the matrix material of mortar and concrete).

\subsection{Mechanical Properties}

The main problem caused by using recycled FRP in cementitious materials appears to be associated with the mechanical performance. Figure 1 presents results from the key prior investigations that have studied the effect of replacing aggregates (fillers) with mechanically recycled FRP on the compressive strength of cementitious materials. In this figure, the reduction or increase in the compressive strength of the concrete or mortar is plotted against the portion of aggregate in the cementitious material, which has been replaced with recycled FRP waste. It is important to point out that in every one of these prior investigations some of the materials, characteristics, specifications, and ratios (weight or volume) used were different so that the data plotted in Figure 1 is intended to show trends in the behavior. Variables in the prior studies included the type of cementitious material (concrete $v s$. mortar), water to cement ratio and mix constituents/proportions of the cementitious material, the type of FRP waste (GFRP vs. CFRP, with different fiber contents and resin types), and finally the size of recycled FRP and the aggregate that were replaced (fine vs. coarse). A clear trend can be seen in the results from the majority of the prior investigations; replacement of aggregates with FRP waste resulted in a significant drop in the 
strength of the cementitious material. The details of the prior work shown in Figure 1 are discussed in what follows.

Figure 1. The effect of replacing aggregates in cementitious materials with fiber reinforced polymer (FRP) waste on the compressive strength of concrete as reported by different investigators. ( $\dagger$ : glass fiber reinforced polymer (GFRP) waste used in self-compacting concrete; $\uparrow \uparrow$ : GFRP waste used in mortar) $[6,31,35,36,38-41]$.

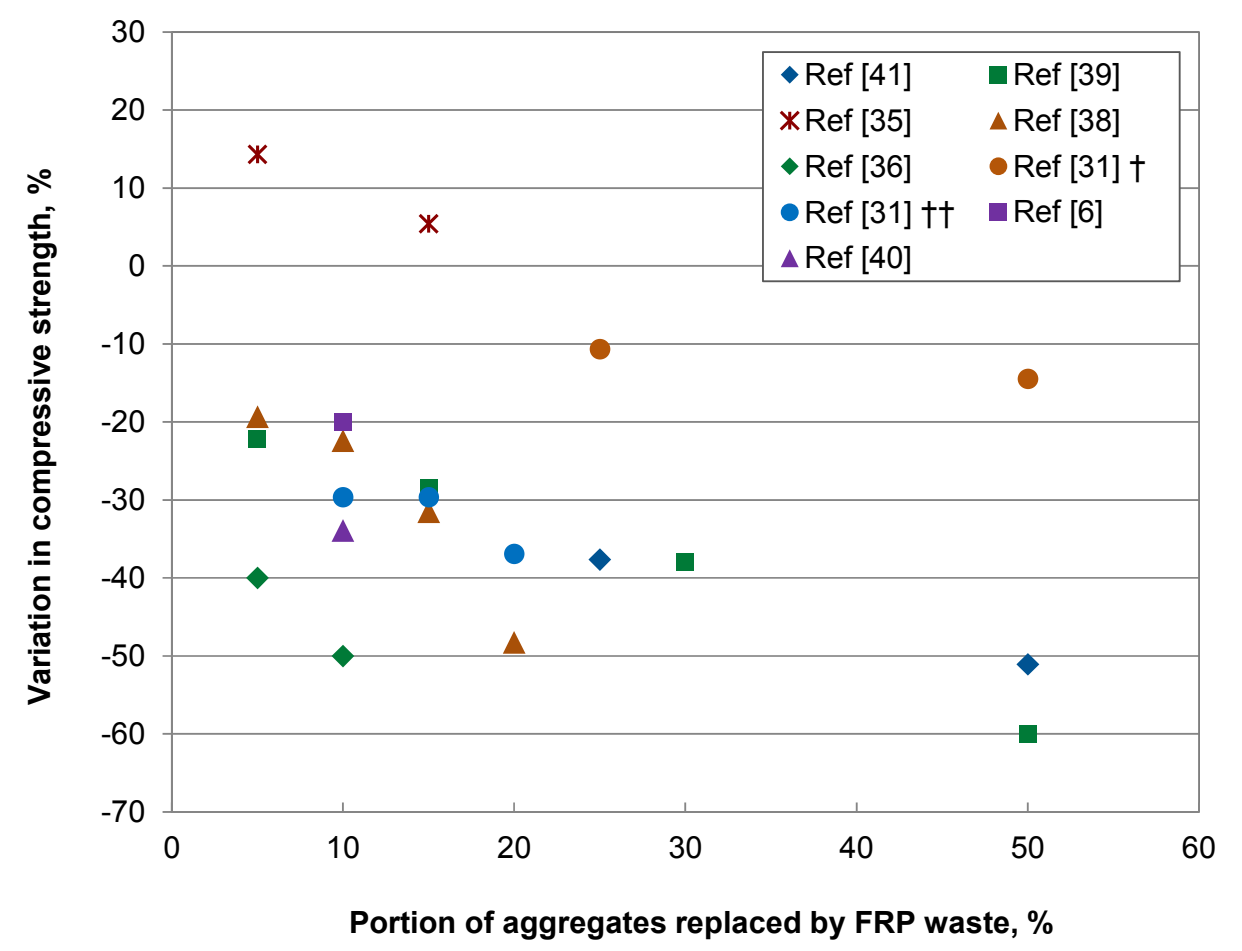

\subsubsection{Replacement of Fine Aggregates}

Asokan et al. [39] used ground GFRP waste powder that passed $2 \mathrm{~mm}$ sieve as a substitute to fine aggregate in concrete. Fifty percent of the GFRP waste powder particles was below $18 \mu \mathrm{m}$ and almost $90 \%$ of the GFRP waste powder particles was below $63 \mu \mathrm{m}$. They produced concrete batches with fine aggregate replacements of $5 \%, 15 \%, 30 \%$, and $50 \%$. They observed a reduction of $60 \%$ in compressive strength when replacing $50 \%$ of the fine aggregate by GFRP. However, the values of $w / c$ ratio for control and 50\% GFRP batches were 0.5 and 0.71 (for the purpose of maintaining a constant concrete workability). Such a reduction in $w / c$ ratio causes an approximately $40 \%$ decrease in compressive strength [42]. Asokan et al. [35] performed another study in which superplasticizer (2.0\% by the weight of cement) was used in concrete batches with $5 \%$ and $15 \%$ replacement of fine aggregates with ground GFRP. Although the concrete batches containing GFRP had slightly higher $w / c$ ratios $(0.37$ and 0.38 in GFRP-incorporated concrete and 0.34 in the control concrete), they had higher compressive strength values compared to control concrete.

Tittarelli et al. [36] used a GFRP powder obtained from a shipyard as an industrial by-product to partially replace the natural silica sand in mortars. The GFRP powder composition was about $20 \%$ by volume of glass fibers and $80 \%$ by volume of polyester resin. SEM observation showed that the powder comprised polymeric granules surrounding the fibers of a low alkali glass. Replacing 5\% and 
$10 \%$ of natural silica sand in mortars with a $w / c$ ratio of 0.5 caused significant reductions of approximately $40 \%$ and $50 \%$ in compressive strength, respectively (based on the graphs presented in their article). The reductions in flexural strength were approximately $17 \%$ and $20 \%$. In another study, Tittarelli and Shah [6] observed that replacing $10 \%$ of natural silica sand with the GFRP powder in mortars with a $w / c$ ratio of 0.50 , resulted in a decrease of $50 \%$ in compressive strength when wet curing was adopted. They observed that when the concrete specimens were dry-cured (as in the open air or in the oven), the mechanical penalization due to GFRP dust addition was partially recovered. A similar observation was made by Asokan et al. [39]. Tittarelli and Moriconi [31] used the GFRP powder as a partial replacement of natural calcareous sand in mortars of higher $w / c$ ratio $(0.62)$. Their results show that replacing $20 \%$ of sand with the GFRP powder resulted in an approximately $35 \%$ decrease in the compressive strength (based on the graphs presented in their article). They also used the GFRP powder to replace $25 \%$ and $50 \%$ of sand in self-compacting concrete with a $w / c$ ratio of 0.62 and observed relatively low values (10\% and $15 \%$, respectively) of decrease in compressive strength.

Correia et al. [38] used the fine particles generated during the production of GFRP products by the cutting of pultruded profiles. Ninety-six percent of the GFRP particles were smaller than $63 \mu \mathrm{m}$. These particles were used as the partial replacement of fine aggregates in concrete. They investigated the volume replacement ratios of $5 \%, 10 \%, 15 \%$, and $20 \%$, and they used the same amount of superplasticizer in control and GFRP batches. Like Asokan et al. [39], they used higher $w / c$ ratios for higher GFRP waste content to maintain a constant workability ( $w / c$ ratios for the control and $20 \%$ GFRP were 0.40 and 0.46 , respectively). They observed reductions of $48 \%$ in compressive strength and $47 \%$ in splitting tensile strength due to replacing $20 \%$ of fine aggregates with GFRP particles. These reductions are in part due to the higher $w / c$ ratio in the GFRP mix.

\subsubsection{Replacement of Coarse Aggregates}

Alam et al. [42] used GFRP scrap that was excess from the composite manufacturing process for casting waterslides. The GFRP was coated with a thin layer of gel to make it smooth. The long strips of the scrap were recycled by simply cutting them into small squares using an abrasive wet tile saw. The recycled GFRP was used to replace portions of ( $25 \%$ and $50 \%$ by volume) coarse aggregate in concrete with a water to cement ratio $(w / c)$ of 0.4 . The GFRP particles and coarse aggregate had similar maximum particle sizes. However, the GFRP particles had similar sizes while the coarse aggregates were well-graded. Replacement of aggregates with recycled GFRP resulted in up to more than $50 \%$ and $40 \%$ decreases in the compressive strength and flexural strength of concrete, respectively. The very smooth surface of the GFRP pieces resulted in a poor bond with mortar and was an important reason for the significant loss of strength in the concrete. The flat shape and poor gradation of the GFRP particles are among other possible reasons for the poor mechanical performance of concrete.

Ogi et al. [43] used recycled CFRP waste as an additional filler in concrete batches with $w / c$ ratio of 0.45. They crushed CFRP to relatively flat pieces of three different size categories with average length by width values of $3.4 \mathrm{~mm} \times 0.4 \mathrm{~mm}, 9.9 \mathrm{~mm} \times 2.2 \mathrm{~mm}$, and $21 \mathrm{~mm} \times 7.7 \mathrm{~mm}$. The thickness of CFRP pieces was in the range of $0.05-0.2 \mathrm{~mm}$. They produced concrete batches with CFRP to coarse aggregate weight ratios ranging from $0 \%$ to $22 \%$ (volume ratios are not reported). The compressive 
and flexural strength test results showed that the incorporation of CFRP did not affect the mechanical properties of concrete significantly. However, it was observed that smaller CFRP particles tended to slightly increase the strength of concrete while the larger CFRP particles tended to slightly reduce the strength of concrete. One possible reason is that the smaller particles had fibrous shapes (higher aspect ratio) (Figure 2); since carbon fibers are very stiff and strong, they can postpone the initiation and opening of cracks, and thereby enhance the strength of concrete.

Figure 2. Recycled CFRF used in concrete by Ogi et al. [43]. Reprinted with permission from [43], copyright 2014, Elsevier.

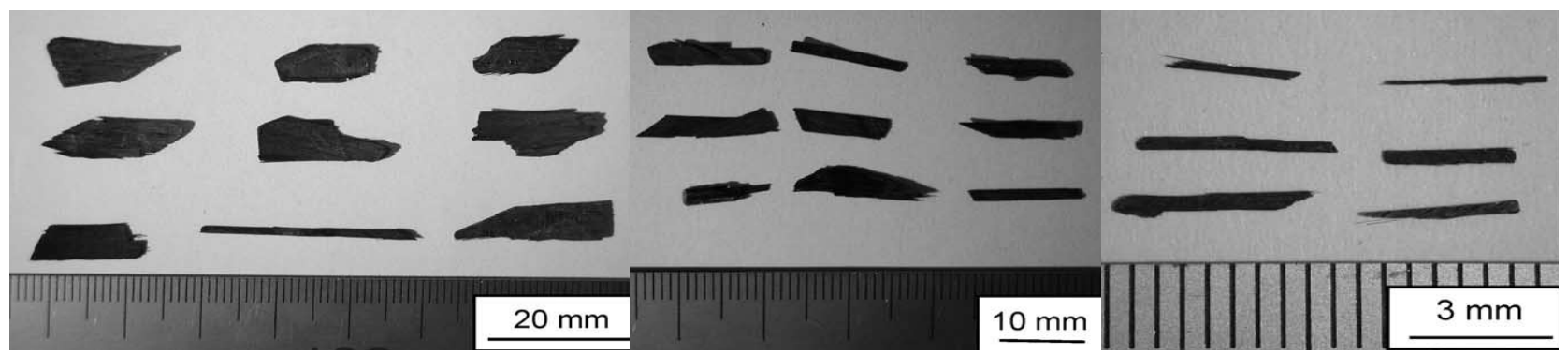

The past work on the properties of FRP waste incorporating cementitious materials is too limited to lead to a conclusion about whether or not using mechanically recycled FRP in concrete or mortars is a viable option. In addition, to assess such an option, the feasibility of use, and the effect of incorporating FRP waste in other composites should be studied in detail. The use of finely ground FRP in materials such as FRP, asphalt, engineered wood and polymer concrete has been researched in the past $[10,17,44-46]$. Some studies have shown that using ground FRP as a filler in new polymeric composite materials can reduce mechanical performance of the new composite [47], while other studies have reported similar or even enhanced properties of polymeric composite materials as a result of incorporating mechanically recycled FRP waste. For example, it has been observed that substitution of up to $88 \%$ of the calcium carbonate filler in sheet molding compounds (SMCs) by fine particulate recycled FRP resulted in materials with comparable strength and stiffness [48]. Inoh et al. [49] reported that replacing up to $20 \%$ of filler in SMC with finely ground SMC does not affect the mechanical performance of the composite material. Kojima and Furukawa [50] observed 30\% improvement in strength when finely ground polymer matrix composite $(15-12 \mu \mathrm{m})$ was used in its own production stream as a replacement for calcium carbonate filler.

\section{Can the Use of FRP Production and End-of-Life Waste in Concrete be Optimized?}

Three filler characteristics affect the mechanical performance of a composite material: (1) strength of the filler, (2) Young's modulus, or in general the stiffness, of the filler, and (3) the filler-matrix interface bond strength. Natural aggregates are the strongest component of normal-strength concrete. Alexander and Mindess [51] have presented a comprehensive list of the mechanical properties of different rocks used as aggregates. The average compressive strength of most rocks is notably above $100 \mathrm{MPa}$, while that of hydrated cement paste even with low $w / c$ ratios is below $100 \mathrm{MPa}$; according to Cong et al. [52] the compressive strength of cement paste with $w / c$ ratios in the range of 0.39 down to 0.30 is from $70 \mathrm{MPa}$ to $100 \mathrm{MPa}$. The failure of concrete carrying increasing compressive stress 
occurs due to the formation and propagation of crack in weakest zones, namely (1) the interfacial transition zone (ITZ), which is the most porous portion of cementitious matrix (hydrated cement) around aggregates, and (2) the cementitious matrix itself.

The strength of FRP materials vary widely depending on the type of the composite. For example, the strength of BMCs can be as low as $30 \mathrm{MPa}$ due to the low dosage of fiber and high dosage of filler, while the strength of FRPs obtained by the Vacuum Assisted Resin Transfer Molding (VARTM) method can be higher than $500 \mathrm{MPa}$ when reinforced with glass fibers or $1000 \mathrm{MPa}$ when reinforced with carbon fibers [1]. In addition, FRP composite materials containing continuous fibers are anisotropic and have different strength values in different directions. For example, the longitudinal compressive strength of the commonly used glass-reinforced pultruded vinylester is in the range of 207-359 MPa while their transverse strength is within 110-138 MPa [53,54]. However, a review of the mechanical properties of all types of FRP indicates that the compressive strength values of FRP materials in the weakest direction are mostly higher than the compressive strength of cement paste. As for stiffness, the compressive Young's modulus of pultruded glass fiber reinforced vinylester in the transverse (least stiff) direction can be as low as $7 \mathrm{GPa}$ which is about half of the estimated compressive Young's modulus of hydrated cement paste. However, the longitudinal compressive Young's modulus of the same FRP is approximately the same as that of hydrated cement paste. Therefore, while FRP composite materials are typically weak in shear, it is possible that the mechanical properties of FRP are not the main or only cause of the reported significant drop in the strength of FRP-waste-incorporated concrete.

The FRP waste used in most of the experimental studies performed on the properties of FRP-incorporated concrete have been in the form of fine powder. An SEM image of such a powder from Tittarelli and Shah [6] is shown in Figure 3. The image shows that the polymer particles and the broken fibers are mostly separated from each other; in other words, a ground FRP particle cannot be regarded as a composite material. When FRP particles are incorporated within the matrix of a new material these particles act independently. Approximately $80 \%$ of the content of the FRP powder used in the studies of Tittarelli and coworkers was polyester resin. Polyester resin has an approximate tensile strength of $65 \mathrm{MPa}$ [4] and its compressive strength is roughly twice as high [55], which means that although polyester resin is weaker than commonly used natural aggregates, it is nearly as strong as hydrated cement. Therefore, the strength of the resin is probably not the major reason for the observed significant reduction in the strength of the mortar when the fine aggregate is partially replaced with the ground FRP. However, the modulus of elasticity of polyester resin (approximately $3 \mathrm{GPa}$ ), and most other thermosetting resins is on average more than 10 times lower than that of natural aggregate and approximately five times lower than that of cement paste. Therefore, due to the resulting low modular ratio, the amount of stress transferred and resisted by resin particles in the concrete is approximately 10 times lower than that of natural aggregates and five times lower than that of the cementitious matrix.

Based on the above discussion, it seems that a better form of FRP waste that can be used as a partial replacement of natural aggregates in concrete is larger particles/pieces with rough surfaces in which fibers and the polymer matrix are well bonded. Experimental investigations are required to confirm this hypothesis as it seems to contradict some findings about incorporating FRP waste particles in polymeric materials; according to DeRosa et al. [48], Dzeskiewicz and Ralston [56] found that when $17.5 \mathrm{wt} \% \mathrm{BMC}$ recyclate with an average size of $0.25 \mathrm{~mm}$ was added to another BMC, tensile strength 
increased slightly over the base formulation, while when $0.50 \mathrm{~mm}$ recyclate was added at $17.5 \mathrm{wt} \%$, a $15 \%$ reduction in tensile strength in the new BMC was observed. However, it is not known if the particles of waste BMC used by Dzeskiewicz and Ralston were in the form of composite or separated ingredients. If the latter is the case, the waste particles consisted of poorly-bonded agglomerates of smaller particle that create weak zones the in matrix of the new BMC.

Figure 3. GFRP powder used by Tittarelli and Shah [6] and relative SEM image. Reprinted with permission from [6], copyright 2014, Elsevier.
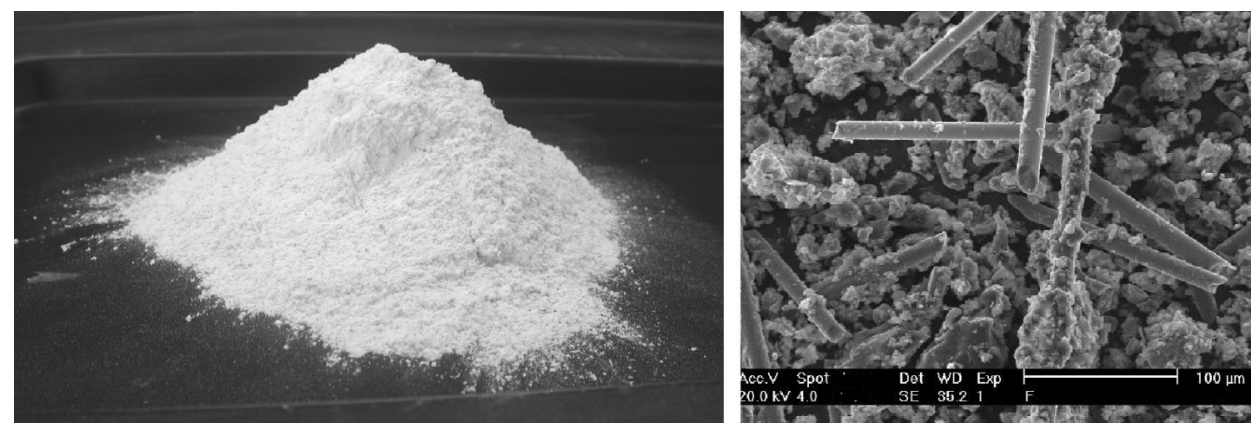

To the knowledge of the authors, two studies have been performed on replacing coarse aggregates with similar-size or large pieces of FRP (reported in Section 3). In the investigations of Alam et al. [42], the excess from the casting of waterslides were used, which were coated with a layer of polymer ("gel-coat") to make them smooth. Figure 4 shows that this smooth surface resulted in a poor bond between the pieces of FRP and concrete matrix, and was the main cause of the poor mechanical performance of the FRP-incorporated concrete. Since all FRP closed mold processes (such as pultrusion, resin-transfer molding (RTM), VARTM) use a release agent to prevent the polymer sticking to the mold upon curing, it is likely that this will be a similar issue with recycled FRP from these processes. The other investigation on incorporating coarse pieces of FRP in concrete was performed by Ogi et al. [43]. They used crushed CFRP with rough surfaces (Figure 2). As can be seen in Figure 2, (1) the FRP particles have rough surfaces, and (2) each particle can be regarded as a composite material. As mentioned earlier, Ogi et al. did not observe any significant reduction in the compressive strength of concrete due to the replacement of natural course aggregate with the CFRP waste. This reinforces the hypothesis of the authors of this article that using coarser FRP waste in which fibers and matrix material are bonded can provide better mechanical performance. To further assess this hypothesis, similar investigations must be performed on FRP waste with different sizes, different fiber types, and different fiber contents.

Recycling the fiber portion of FRP production waste and using it as aggregate in cementitious materials is another possible option to manage the waste from the FRP industry. Producing GFRP parts by the pultrusion process results in a significant amount of waste glass rovings and mats (Figure 5). Instead of landfilling, which is the common practice in the U.S., the rovings can be recycled and reused by (1) melting procedures to produce new glass products [57], or (2) cut into discrete fibers, or ground into powder and used in the production of new materials. The use of glass fibers in cementitious materials have been commercialized since the 1970s [58]. Glass fibers have been widely used in mortars to produce thin sheet architectural components such as building facades and in concrete for reducing plastic shrinkage cracking [59]. A main concern with using glass fibers in concrete is that they may lose strength (and therefore the reinforcing capacity) rather quickly due to the 
very high alkalinity $(\mathrm{pH} \geq 12.5)$ of the cement-based matrix [60]. However, alkali-resistant glass fibers (AR-glass fibers) have been developed that provide improved long-term durability. Therefore, it is important to investigate the resistance of glass rovings currently used (such as Boron-free E-CR glass rovings [61-63]) for producing GFRP, and compare it with that of AR-glass fibers. It should be mentioned that there are different methods for lowering the alkalinity level of the cementitious matrix (e.g., by adding silica fume or metakaolin) to enhance the durability of glass fibers in concrete. Some of those methods are outlined in the ACI report on fiber reinforced concrete [58].

Figure 4. Fractured surface of concrete incorporating pieces of FRP scrap used by Alam et al. [42] as a partial replacement of coarse aggregate.

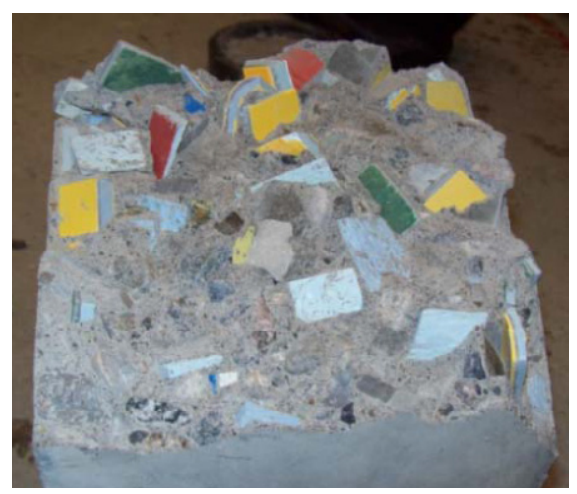

Figure 5. Unused glass rovings and mats after the production of GFRP parts using the pultrusion method, from two FRP manufacturers: (a) Strongwell, and (b,c) Creative Pultrusions.

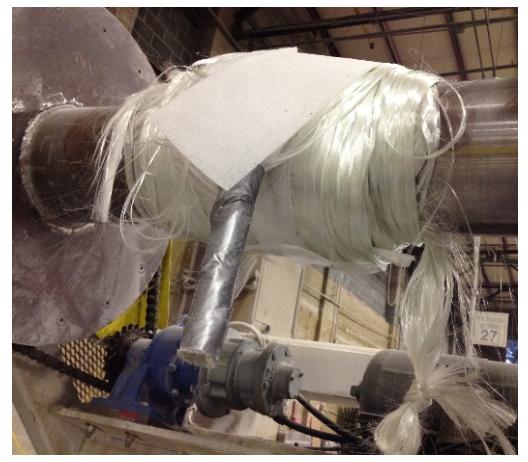

(a)

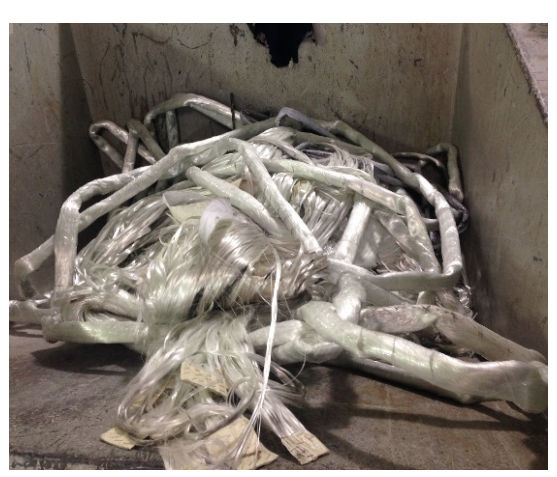

(b)

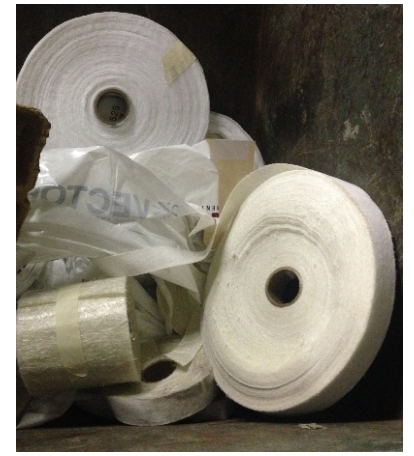

(c)

Using ground glass fibers/mats in concrete and mortars is another potential FRP waste management option. As mentioned earlier, Tittarelli and Moriconi [31] investigated the alkali-silica reactivity of finely ground GFRP and did not find any potential deleterious reactivity due to the glassy part present in the waste. Rajabipour et al. [64] used scanning electron microscopy (SEM) with X-ray energy dispersive spectroscopy (EDS) capability, as well as the ASTM C1260 [65] mortar bar method to investigate the role of glass particle size on their alkali silica reactivity in cementitious matrices. They observed that for particles smaller than $0.6 \mathrm{~mm}$, the ASR is minimal and insignificant. Based on these findings it is expected that the use of ground waste glass rovings and mats will not cause ASR in cementitious materials. 
Finally, while using recycled waste in any form may reduce the performance of new materials incorporating the waste, this by itself is not necessarily the crux of the issue in the authors' opinion. For example, the strength reduction in concrete caused by the partial replacement of aggregates with recycled FRP can be compensated for by changing concrete mix proportions. In our opinion, the major issues associated with the use of recycled waste in new materials are (1) the unknown properties of the source material that has been recycled, and (2) the potentially high variation in the properties of recycled materials supplied to a concrete production plant. Since a recycling plant receives waste materials from different, and possibly changing, sources, the batch-to-batch compositions of the recycled materials can be different. That results in higher variations in the properties and performance of the materials incorporating waste.

This issue can be resolved or mitigated in three ways: (1) using waste with known properties before combining it with the waste from other sources; and (2) developing criteria and procedures for characterizing the properties of the recycled waste materials.

The first method is implementable mostly on production waste. An example is recycling the waste glass rovings from the production of pultruded FRP (Figure 5). The properties of these fibers are known by the manufacturer and the waste rovings can be recycled (e.g., by grinding to powder), before being stored and mixed with other types of waste, to produce fillers with constant quality. In the second approach, a set of material tests are selected and performed on the recycled waste to (a) measure the physical and geometric properties, (b) determine the types and amounts of impurities, (c) characterize the composition. Then, based on performance tests on the waste-incorporated composite material, a set of limits on the material test results will be established, which if not exceeded the waste is regarded as usable for producing the new composite material. FRP waste can be examined by (a) visual observations to find the amounts of different visible impurities, (b) optical and electron microscopy to determine the portions of fiber, polymeric matrix materials, smaller impurities, and voids, and (c) spectroscopy and diffraction methods, such as XRD, XRF, Raman spectroscopy, etc., to determine the constituents and types of fibers, matrix materials, and impurities.

\section{Conclusions}

The critical review and discussion presented in this article leads to a number of important conclusions:

- Landfilling FRP waste is still the easiest and cheapest method for managing FRP waste in most countries, including the U.S. However, environmental regulations are becoming tighter and it is expected that landfilling FRP will become more restricted, as it already is in several countries, including Germany.

- The most researched application of mechanically recycled FRP waste is its use as a partial replacement of fillers in new FRP composite materials. This usually reduces the mechanical properties of the new composite material.

- Partial replacement of aggregates in concrete and mortars is another potential application of mechanically recycled FRP. The few investigations performed on this topic suggest that recycled FRP fillers do not notably affect the durability of cementitious materials, but significantly reduce their mechanical properties. 
- In most of the experimental studies on the mechanical properties of FRP-waste-incorporated concrete and mortars, finely ground FRP particles have been used as a partial replacement of aggregates. Finely ground FRP waste particles consist of poorly bonded pieces of polymer resin and fibers. Since polymer resin particles have a low stiffness, if the FRP waste has a high resin content, it can significantly reduce the strength of concrete or mortars.

- It was hypothesized that using larger FRP aggregates with rough surface will have a much smaller adverse effect on the mechanical properties of cementitious materials. In some types of FRP waste, this will require removing the gel coat or release agents from the material surface in order to improve the bond between the FRP pieces and the cement matrix. However, this option might not be feasible.

- To determine if using FRP waste in concrete is a viable option, further investigations must be performed on both durability and mechanical properties. In addition, for use in structural concrete, the fire resistance and mechanical performance of the FRP-waste-incorporated concrete at high temperatures should be investigated.

\section{Acknowledgments}

The authors wish to thank Dustin Troutman and Ronald Allison from Creative Pultrusions and Glenn Barefoot from Strongwell, for providing technical information and support.

\section{Conflicts of Interest}

The authors declare no conflict of interest

\section{References}

1. Reynolds, N.; Pharaoh, M. An introduction to composites recycling. In Management, Recycling and Reuse of Waste Composites; Goodship, V., Ed.; Woodhead Publishing: Cambridge, UK, 2010; pp 3-19.

2. Murphy, J. Additives for Plastics Handbook; Elsevier B.V.: Amsterdam, The Netherlands, 2001.

3. The Official Webpage of the American Composites Manufacturers Association (ACMA), Market Overview. Available online: http://www.acmanet.org/the-industry/market-overview (accessed on 5 June 2014).

4. Bank, L.C. Composites for Construction: Structural Design with FRP Materials; John Wiley \& Sons, Inc.: Hoboken, NJ, USA, 2006.

5. Where Do GRP Boats Go at the End of Their Service Life? Available online: http://www.reinforcedplastics.com/view/34805/where-do-grp-boats-go-at-the-end-of-their service-life/ (accessed on 5 June 2014).

6. Tittarelli, F.; Shah, S.P. Effect of low dosages of waste GRP dust on fresh and hardened properties of mortars: Part 1. Constr. Build. Mater. 2013, 47, 1532-1538.

7. US Demand for Fibre Reinforced Plastic Composites to Rise. Available online: http://www.reinforcedplastics.com/view/35326/us-demand-for-fibre-reinforced-plastic-compositesto-rise (accessed on 5 June 2014). 
8. Composites Market Report. Available online: http://www.pultruders.com/files/pultruders.com/ Documents/market_report_2013.pdf (accessed on 5 June 2014).

9. Osmani, M.; Asokan, P. An assessment of the compressive strength of glass reinforced plastic waste filled concrete for potential applications in construction. Concr. Res. Lett. 2010, 1, 1-5.

10. Pickering, S.J. Recycling technologies for thermoset composite materials-Current status. Compos. A Appl. Sci. Manuf. 2006, 37, 1206-1215.

11. Bains, M.; Carruthers, J. Composite Materials Resource Efficiency Action Plan (REAP); Report 021; The Green Construction Board, UK, 2013.

12. Potter, K.; Ward, C. In-process composite recycling in the aerospace industry. In Management, Recycling and Reuse of Waste Composites; Goodship, V., Ed.; Woodhead Publishing: Cambridge, UK, 2010; pp. 458-494.

13. Halliwell, S. FRPs - The Environmental Agenda. Adv. Struct. Eng. 2010, 13, 783-791.

14. Job, S. Recycling glass fibre reinforced composites-History and progress. Reinf. Plast. 2013, 57, $19-23$.

15. Cunliffe, A.M.; Williams, P.T. Characterisation of products from the recycling of glass fibre reinforced polyester waste by pyrolysis. Fuel 2003, 82, 2223-2230.

16. Broekel, J.; Scharr, G. The specialities of fibre-reinforced plastics in terms of product lifecycle management. J. Mater. Process. Technol. 2005, 162-163, 725-729.

17. Meira Castro, A.C.; Carvalho, J.P.; Ribeiro, M.C.S.; Meixedo, J.P.; Silva, F.J.G.; Fiúza, A.; Dinis, M.L. An integrated recycling approach for GFRP pultrusion wastes: Recycling and reuse assessment into new composite materials using Fuzzy Boolean Nets. J. Clean. Prod. 2014, 66, 420-430.

18. Breakthrough at the FRP Recycling. Available online: http://www.zajonszerkleinerung.de/index.php/en/compocycle (accessed on 5 June 2014).

19. Pimenta, S.; Pinho, S.T. Recycling carbon fibre reinforced polymers for structural applications: Technology review and market outlook. Waste Manag. 2011, 31, 378-392.

20. Black, S. Reselling, Reusing Composite Materials and Parts. Available online: http://www.compositesworld.com/blog/post/reselling-reusing-composite-materials-and-parts (accessed on 5 June 2014).

21. Wood, K. Carbon Fiber Reclamation: Going Commercial. Available online: http://www.compositesworld.com/articles/carbon-fiber-reclamation-going-commercial (accessed on 5 June 2014).

22. Grause, G.; Mochizuki, T.; Kameda, T.; Yoshioka, T. Recovery of glass fibers from glass fiber reinforced plastics by pyrolysis. J. Mater. Cycles Waste Manag. 2013, 15, 122-128.

23. Shima, H.; Takahashi, H.; Mizuguchi, J. Recovery of glass fibers from fiber reinforced plastics. Mater. Trans. 2011, 52, 1327-1329.

24. Yoon, K.Y.; Lee, S.H. Developing advanced practical recycling method of FRP boats. In Proceedings of the OCEANS'12 MTS/IEEE Yeosu Conference, Yeosu, Korea, 21-24 May 2012; pp. 1-7.

25. Marsh, G. Reclaiming value from post-use carbon composite. Reinf. Plast. 2008, 52, 36-39. 
26. Kennerley, J.R.; Kelly, R.M.; Fenwick, N.J.; Pickering, S.J.; Rudd, C.D. The characterisation and reuse of glass fibres recycled from scrap composites by the action of a fluidised bed process. Compos. A Appl. Sci. Manuf. 1998, 29, 839-845.

27. Goto, M. Chemical recycling of plastics using sub- and super-critical fluids. J. Supercrit. Fluids 2009, 47, 500-507.

28. Adams, R.D.; Collins, A.; Cooper, D.; Wingfield-Digby, M.; Watts-Farmer, A.; Laurence, A.; Patel, K.; Stevens, M.; Watkins, R. Recycling of reinforced plastics. Appl. Compos. Mater. 2014, 21, 263-284.

29. Palmer, J.; Ghita, O.R.; Savage, L.; Evans, K.E. Successful closed-loop recycling of thermoset composites. Compos. A Appl. Sci. Manuf. 2009, 40, 490-498.

30. Hedlund-Astrom, A. Model for End of Life Treatment of Polymer Composite. Ph.D. Thesis, Royal Institute of Technology, Stockholm, Sweden, 21 October 2005.

31. Tittarelli, F.; Moriconi, G. Use of GRP industrial by-products in cement based composites. Cem. Concr. Compos. 2010, 32, 219-225.

32. Standard Test Method for Potential Alkali-Silica Reactivity of Aggregates (Chemical Method); Active Standard ASTM C289; American Society for Testing Material (ASTM) International: West Conshohocken, PA, USA, 2007.

33. Jo, B.-W.; Park, S.-K.; Kim, C.-H. Mechanical properties of polyester polymer concrete using recycled polyethylene terephthalate. ACI Struct. J. 2006, 103, 219-225.

34. Guide for the Design and Construction of Structural Concrete Reinforced with FRP Bars; ACI 440.1R-06; American Concrete Institute (ACI): Farmington Hills, MI, USA, 2006.

35. Asokan, P.; Osmani, M.; Price, A.D.F. Improvement of the mechanical properties of glass fibre reinforced plastic waste powder filled concrete. Constr. Build. Mater. 2010, 24, 448-460.

36. Tittarelli, F.; Kawashima, S.; Tregger, N.; Moriconi, G.; Shah, S.P. Effect of GRP by-product addition on plastic and hardened properties of cement mortars. In Proceedings of the Second International Conference on Sustainable Construction Materials and Technologies, Ancona, Italy, 28-30 June 2010; pp. 677-687.

37. Tittarelli, F. Effect of low dosages of waste GRP dust on fresh and hardened properties of mortars: Part 2. Constr. Build. Mater. 2013, 47, 1539-1543.

38. Correia, J.R.; Almeida, N.M.; Figueira, J.R. Recycling of FRP composites: Reusing fine GFRP waste in concrete mixtures. J. Clean. Prod. 2011, 19, 1745-1753.

39. Asokan, P.; Osmani, M.; Price, A.D.F. Assessing the recycling potential of glass fibre reinforced plastic waste in concrete and cement composites. J. Clean. Prod. 2009, 17, 821-829.

40. Coppola, L.; Cadoni, E.; Forni, D.; Buoso, A. Mechanical characterization of cement composites reinforced with fiberglass, carbon nanotubes or glass reinforced plastic (GRP) at high strain rates. In Proceedings of the 3rd International Workshop on Performance, Protection and Strengthening of Structures under Extreme Loading, Lugano, Switzerland, 30 August-1 September 2011; pp. 190-195.

41. Shahria Alam, M.; Slater, E.; Muntasir Billah, A. Green concrete made with RCA and FRP scrap aggregate: Fresh and hardened properties. J. Mater. Civ. Eng. 2013, 25, 1783-1794.

42. Kosmatka, S.H.; Wilson, M.L. Design and Control of Concrete Mixes. In Designing and Proportioning Concrete Mixtures; Portlan Cement Association (PCA): Washington, DC, USA, 2011. 
43. Ogi, K.; Shinoda, T.; Mizui, M. Strength in concrete reinforced with recycled CFRP pieces. Compos. A Appl. Sci. Manuf. 2005, 36, 893-902.

44. Conroy, A.; Halliwell, S.; Reynolds, T. Composite recycling in the construction industry. Compos. A Appl. Sci. Manuf. 2006, 37, 1216-1222.

45. Henshaw, J.M.; Han, W.; Owens, A.D. An overview of recycling issues for composite materials. J. Thermoplast. Compos. Mater. 1996, 9, 4-20.

46. Ribeiro, M.C.S.; Meira-Castro, A.C.; Silva, F.G.; Santos, J.; Meixedo, J.P.; Fiuza, A.; Dinis, M.L.; Alvim, M.R. Re-use assessment of thermoset composite wastes as aggregate and filler replacement for concrete-polymer composite materials: A case study regarding GFRP pultrusion wastes. Resour. Conserv. Recycl. 2013, 2013, doi:10.1016/j.resconrec.2013.1010.1001.

47. Bledzki, A.K.; Goracy, K. The use of recycled fibre composites as reinforcement for thermosets. Mech. Compos. Mater. 1994, 29, 352-356.

48. Derosa, R.; Telfeyan, E.; Mayes, J.S. Current state of recycling sheet molding compounds and related materials. J. Thermoplast. Compos. Mater. 2005, 18, 219-240.

49. Inoh, T.; Yokoi, T.; Sekiyama, K.-I.; Kawamura, N.; Mishima, Y. SMC Recycling Technology. J. Thermoplast. Compos. Mater. 1994, 7, 42-55.

50. Kojima, A.; Furukawa, S. Recycling of resin matrix composite materials VII: Future perspective of FRP recycling. Adv. Compos. Mater. 1997, 6, 215-225.

51. Alexander, M.; Mindess, S. Aggregates in Concrete; CRC Press: Boca Raton, FL, USA, 2005.

52. Cong, X.; Gong, S.; Darwin, D.; McCabe, S.L. Role of silica fume in compressive strength of cement paste, mortar, and concrete. ACI Mater. J. 1992, 89, 375-387.

53. Strongwell Design Manual (CD ROM). Available online: http://www.strongwell.com (accessed on 5 June 2014).

54. The Pultex Pultrusion Global Design Manual, 4th ed. Available online: http://www.creativepultrusions.com (accessed on 5 June 2014).

55. Guide to Glass Reinforced Plastic (GRP). Available online: http://www.ecfibreglasssupplies.co.uk/ t-GlassReinforcedPlastics.aspx (accessed on 5 June 2014).

56. Dzeskiewicz, L.A.; Ralston, J.D. Evaluation of regrind in thermoset applications. In Proceedings of the 52nd Annual Technical Conference of the Society of Plastics Engineers, Newtown, CT, USA, 1-5 May 1994.

57. PPG Installs Waste Glass Recycling Unit at Netherlands Fiber Glass Manufacturing Site. Available online: http://www.ppg.com/en/newsroom/news/Pages/20060515.aspx\#sthash.6dqqXGVx.dpuf (accessed on 5 June 2014).

58. Report on Fiber Reinforced Concrete; ACI 544.1 R-96; American Concrete Institute (ACI): Farmington Hills, MI, USA, 2009.

59. Cem-FIL ${ }^{\circledR}$ Glass Fiber, the Solution for Concrete Reinforcement. Available online: http://www.ocvreinforcements.com/Cemfil/ (accessed on 5 June 2014).

60. Larner, L.J.; Speakman, K.; Majumdar, A.J. Chemical interactions between glass fibres and cement. J. NonCryst. Solids 1976, 20, 43-74.

61. E-CR Glass Roving. Available online: http://www.compositesworld.com/products/e-cr-glassroving (accessed on 5 June 2014). 
62. Hybon 2002 CR-Innofiber (Product Description). Available online: http://www.ppg.com/ glass/fiberglass/innofiber/pages/innofibercr.aspx (accessed on 5 June 2014).

63. Advantex ${ }^{\circledR}$ Boron-Free E-CR Glass Reinforcement Properties. Available online: http://www.ocvreinforcements.com/pdf/library/Advantex_ECR_glass_properties_ww_201004_w eb.pdf (accessed on 5 June 2014).

64. Rajabipour, F.; Maraghechi, H.; Fischer, G. Investigating the alkali-silica reaction of recycled glass aggregates in concrete materials. J. Mater. Civ. Eng. 2010, 22, 1201-1208.

65. Standard Test Method for Potential Alkali Reactivity of Aggregates (Mortar-Bar Method); ASTM C1260; American Society for Testing Material (ASTM) International: West Conshohocken, PA, USA, 2007.

(C) 2014 by the authors; licensee MDPI, Basel, Switzerland. This article is an open access article distributed under the terms and conditions of the Creative Commons Attribution license (http://creativecommons.org/licenses/by/3.0/). 